\title{
Association of Polymorphism in Growth and Differentiation Factor 5 Gene with Osteoarthritis Knee
}

\author{
${ }^{1}$ Abhishek Mishra, ${ }^{1}$ Divya Sanghi, ${ }^{1}$ Amar Chandra Sharma, \\ ${ }^{1}$ Saloni Raj, ${ }^{2}$ Shailendra Shanker Maurya, ${ }^{3}$ Sachin Avasthi, \\ ${ }^{1}$ Ajai Singh, ${ }^{2}$ Devendra Parmar and ${ }^{1}$ Rajeshwar Nath Srivastava \\ ${ }^{1}$ Department of Orthopaedic Surgery, CSM Medical University, Lucknow (UP), India \\ ${ }^{2}$ Developmental Toxicology Division, Indian Institute of Toxicology Research, Lucknow, UP, India \\ ${ }^{3}$ Department of Orthopaedic Surgery, GSVM Medical College, Kanpur (UP), India
}

Received 2012-07-19, Revised 2013-01-02; Accepted 2013-01-18

\begin{abstract}
The present study investigated to identify the association of polymorphism in GDF-5 gene with osteoarthritis in North Indian population. In a case-control study, 300 cases with knee osteoarthritis and an equal number of age and gender matched healthy controls were included. Cases were diagnosed using the ACR Guidelines of Knee Osteoarthritis (KOA). Clinical symptoms were assessed with the knee specific WOMAC index and VAS for knee pain. The severity of disease was determined by radiological KL grades (Kellgren Lawren). The variant genotype of GDF-5 was found to be present at significantly higher frequency in cases than in controls, resulting in about 1.79 fold increase in risk to OA. Genotype distributions of the GDF-5 also showed significant association of variant allele with clinical score of OA patients. An association between the+104T/C GDF5 polymorphism with knee OA and clinical symptom of $\mathrm{OA}$ in Indian population further demonstrate a strong genetic influence of this SNP in KOA.
\end{abstract}

Keywords: Polymorphism in GDF-5, Clinical Symptoms, Knee Osteoarthritis, Indian Population

\section{INTRODUCTION}

Osteoarthritis (OA), characterized by gradual loss of articular cartilage in the joint, is a leading cause of disability among the elderly people (Altman, 2011; Ding et al., 2008). Though the etiology and pathogenesis of OA is largely unknown, OA is a chronic degenerative condition of mobile joints, primarily a non-inflammatory disorder characterized by an imbalance between the synthesis and degradation of articular cartilage leading to classic pathological change of wearing away and destruction of cartilage (Brandt et al., 2009). It has been observed that about $80 \%$ of population has radiographic evidence of OA by the age of 65 years, although only about $60 \%$ of these were symptomatic (Green, 2001).
Epidemiological profile of OA in India is not very clear but it is estimated that more than $30-40 \%$ of our population suffer from osteoarthritis beyond the age of 50 years (Sharma et al., 2007). Hip and knee OA represent a huge healthcare burden to society and a personal burden to individuals affected by the disease, in addition to being the main cause of the increasing need for joint replacements (Valdes and Spector, 2011).

Though the mechanism underlying the development $\mathrm{OA}$ is yet to be understood, several biochemichal pathways have been found to be associated with the development of OA (Tchetina, 2011; Valdes and Spector, 2009). An early OA articular cartilage degeneration is associated with increased collagenase cleavage of type II collagen (Buckwalter and Mankin, 1998; Tchetina et al., 2006). Collagenases (MMP-1, 
MMP-14 MT1-MMP), aggrecanase ADAMTS-5, cytokines chondrocyte terminal differentiation-related genes and caspase 3 are reported to be upregulated in the vicinity of the lesion (Hardingham et al., 1992; Watanabe et al., 1998; Tetlow et al., 2001; Aigner and Stove, 2003). The most severely damaged rodent knee $\mathrm{OA}$ articular cartilage has shown to be significantly associated with reduced expression of proliferationrelated growth factors and their signaling molecules such as PTHrP, TGF $\beta 3$ and Smad-2P, TGF $\beta 1$ and its receptor II (Gomez-Barrena et al., 2004; Davidson et al., 2006).

Genetic polymorphism in MMP-1 $(-1,607$ G/2G), MMP-2 (-1,306 C/T) and MMP-9 (-1,562 C/T), associated with increased transcriptional activity has shown to be involved in inhancing the susceptibility to knee osteoarthritis (Barlas et al., 2009). Likewise, allelic variants of ASPN, CALM-1, COL2A1, COMP and ESR$\alpha$, GDF-5, VDR, ADAM12 and BMP2 have been reported to be associated with knee OA. (Bergink et al., 2003; Mabuchi et al., 2003; Jin et al., 2004; Kizawa et al., 2005; Valdes and Spector, 2009). Growth and differentiation factor 5 (GDF-5), also known as cartilage derived morphogenetic protein of Transforming Growth Factor-b (TGF-b) superfamily, plays an important role in the development, maintenance and repair of bone and cartilage. It has been shown that reduced transcriptional activity leads to decrease in cartilage synthesis (Francis-West et al., 1999; Hatakeyama et al., 2004; Southam et al., 2007) and to compensate for the cartilage space, the bone beneath thickens and spreads out form knobbly outgrowths (osteophytes).

As polymorphism in GDF-5 may lead to decreased cartilage synthesis, attempts were made in the present study to explore the association of genetic polymorphism in GDF5 with OA in North Indian population. Attempts were also made to correlate variant $\mathrm{T}$ allele of GDF-5 with clinical profile of OA by associates GDF-5 polymorphism with one of the most widely utilized self-report measures of lower extremity symptoms and function, the Western Ontario Mac University (WOMAC) index and Visual Analogue Scale (VAS) for knee pain.

\section{MATERIALS AND METHODS}

\subsection{Study Subjects}

This Case control study consisted of men and women $\geq 40$ years that fulfilled American College of Rheumatology (ACR) (Sanghi et al., 2011) clinical and radiographic criteria for KOA. Cases (300) and equal no of controls were recruited from the outpatient clinic of the Department of Orthopaedic Surgery of C. S. M. Medical University. The patients and controls were matched for age and sex. These patients were profiled for demographic, clinical, radiological and biochemical features. Age and sex were self reported. Patients were weighed with a calibrated balance beam scale to the nearest $0.1 \mathrm{~kg}$ in minimum possible clothing and standing height was measured (shoes and shocks) with a Stadiometer in centimeters (cm). Body Mass Index (BMI) was recorded by Quetelet index. Among the cases 104 were men and 196 were women and age range from $40-72$, mean age $54.49 \pm 9.24$ and $53.75 \pm 8.47$ years respectively. In the controls 123 were male with mean age $54.50 \pm 7.61$ years and 177 female with mean age $55.65 \pm 8.59$ years. The protocol for research work was approved by the human ethics committee of C.S.M. Medical University, Lucknow. The protocol conforms to the provisions of the declaration of Helsinki in 1995. Informed consent was obtained from the study subjects for inclusion in the study and before the collection of blood samples and it was also ensured that subject anonymity was preserved. The control and cases were asked to fill up the detailed questionnaire regarding their occupation, socioeconomic status, medical history, life style habits. The Kellgren-Lawrence grade represents disease severity, as reflected on radiographs, Radiographic findings of OA were classified into mild (K-L grade 2), moderate (K-L grade 3 ) severe (K-L grade 4).Number of participants in KL grades 2, 3 and 4 were 71,174 and 55, respectively. Average BMI was $25.52 \pm 3.58$. Symptoms related to KOA were assessed with the knee-specific WOMAC index (Bellamy, 1989), which assess pain (five items), stiffness (two items), function (17 items) and interpretation response in terms of a 5-point scale (0, none; 1 , slight; 2 , moderate; 3 , severe; 4 , extreme). Knee pain was also assessed using the VAS, where higher scores indicate worse status.

\subsection{DNA Isolation and Genotype Analysis}

Approximately $1 \mathrm{ml}$ of blood was collected into citrate containing tubes from all the subjects. DNA was isolated from whole blood with the Flexi Gene DNA kit (Qiagen, CA) following the manufacturer's protocol. Isolated DNA was subsequently used for genotyping studies.

\subsection{Detection of GDF-5 Gene Polymorphisms}

The method of (Southam et al., 2007) was followed for determining the GDF-5 gene BSiE1 (T/C; rs143383) polymorphism, In brief, the reaction mixture in $25 \mu \mathrm{L}$ contained $10 \mathrm{X}$ buffer, $1.5 \mathrm{mM} \mathrm{MgCl}_{2}$, dNTPs (10mM) 
$0.2 \mathrm{mM}, 0.5 \mu \mathrm{L}$ of $10 \mathrm{pmol}$ of each primer, $1.5 \mathrm{U}$ of Taq polymerase (MBI Fermentas, Germany), $100 \mathrm{ng}$ of genomic DNA and sterile MilliQ water. Amplification was performed on GeneAmp PCR system 9700 (Applied Bio System) using the following protocol: $94^{\circ} \mathrm{C}$ for 5 min for initial denaturation followed by 35 cycles of $94^{\circ} \mathrm{C}$ for $60 \mathrm{~s}$, annealing at $51^{\circ} \mathrm{C}$ for $45 \mathrm{~s}$, extension at $72^{\circ} \mathrm{C}$ for $1 \mathrm{~min}$ and final elongation step of $72^{\circ} \mathrm{C}$ for 10 min. PCR reaction resulted in a 197 bp product. PCR products $(10 \mu \mathrm{L})$ were digested with $10 \mathrm{U}$ of $\mathrm{BSiE} 1$ restriction enzyme (MBI Fermentas, Germany) to identify the presence of polymorphic sites in GDF-5 gene. Digestion of 197 bp PCR product of GDF-5 gene with BSiE1 restriction enzyme into two fragments of $106 \mathrm{bp}$ and $91 \mathrm{bp} \mathrm{bp}$ indicates the presence of $\mathrm{CC}$ genotype of GDF-5 gene BSiE1 polymorphism. The presence of fragments of three sizes (197, 106 and $91 \mathrm{bp})$ was indicative of the CT genotype while the undigested 197 bp PCR fragment was indicative of TT genotype of BSiE1 polymorphism of GDF-5 gene.

\subsection{Statistical Analysis}

Genotype or allele frequencies of GDF-5 gene of BSiE1 polymorphism among cases and controls were determined for Hardy-Weinberg Equilibrium (HWE) using standard chi square Table 2 statistics. Using binary logistic regression models, we determined the relationship of BSiE1 polymorphism of GDF-5 gene with risk of. All statistical analysis was performed with the SPSS software package (version 16.0 for windows; SPSS Chicago, IL). The power of the present study was found to be $>80 \%$ as analyzed by power genetic association analysis software (http://dceg.cancer.gov/bb/tools/pga) at the level of significance $=0.05$ with sample size of 300 controls, 300 patients.

\section{RESULTS}

The main characteristic of study population age, sex, BMI and clinicoradiological severity are summarized in Table 1. The genotype distribution of the polymorphic GDF-5 in the 5-UTR (BSiE1, C/T) in controls and cases is summarized in. The genotypes of GDF-5 in controls were found to be in Hardy-Weinberg Equilibrium (HWE). As evident from the Table 2 the frequency of TT genotype was higher in cases $(41.33 \%)$ when compared to the controls $(28.00 \%)$. This increase in the frequency of TT genotypes significantly increased the risk $\{\mathrm{OR}: 1.79,(1.14-2.89)$, $\mathrm{p}$ value $=0.016)\}$ for KOA in cases when compared the controls. When the cases were stratified on the basis of gender, the frequency of
TT genotype was significantly increased in cases $(43.26 \%)$ in men when compared to the controls $(30.81 \%)$ significantly increase the risk \{OR: 2.43, (1.01-5.83), 0.046$\}$ to OA in male cases. In females, the frequency TT genotype was also higher in cases $(40.30 \%)$ when compared to the controls (26.55\%), though the increase in risk \{OR: 1.63, (0.93-3.02)\} was found to be relatively less when compared to the risk observed in male cases. Percentage of risk allele $\mathrm{T}$ was higher in cases $63 \%$ when compared with controls $54.66 \%$. The frequency of variant allele $\mathrm{T}$ was also found to be increased in both male and female cases ( 66.82 in male and $60.90 \%$ in female) when compared with controls (56.91\% in male and $53.10 \%$ in female).

Polymorphism in GDF-5 was also associated with clinical symptoms of $\mathrm{OA}$ such as the knee specific WOMAC index and VAS for knee pain. OA patients who are functionally or symptomatically poor (poor index) are defined as those with a WOMAC index score and VAS more than 33 and 6 while those with WOMAC index score and VAS less than or equal to 33 and 6 are classified as functionally or symptomatically good (good index). Cases with variant genotype of the GDF-5 had WOMAC index and VAS score of 43.31 and $40.45 \%$ respectively. In contrast cases with CC genotype of the GDF-5 had WOMAC index and VAS score of 14.64 and $15.45 \%$ respectively (Table 3). A summary of association of GDF5 polymorphisms with radiological features is depicted in Table 4.The polymorphism was significantly associated with the individual radiological features of OA knee. There was a significant difference between patients with osteophyte and without osteophyte in right knee $\left(\chi^{2}=9.04\right.$; $\mathrm{P}=0.011)$ but not between patients with osteophyte in left knee. Likewise juxtraarticular ostopenia was significantly associated in right knee $\left(\chi^{2}=6.93 ; \mathrm{P}=0.031\right)$ but not in left knee (Table 4). Articular incongruity was significantly associated with both knees. However, no significant association was found with other radiological score.

Table 1. Characteristics of the study population

\begin{tabular}{lll}
\hline & Cases $(300)$ & Controls (300) \\
\hline Age (mean $\pm \mathrm{SD}$, years) & $54.01 \pm 8.74$ & $55.18 \pm 8.21$ \\
Male age (mean $\pm \mathrm{SD}$, years) & $54.49 \pm 9.24$ & $54.50 \pm 7.61$ \\
Female age (mean $\pm \mathrm{SD}$, years) & $53.75 \pm 8.47$ & $55.65 \pm 8.59$ \\
BMI (mean $\left.\pm \mathrm{SD}, \mathrm{kg} / \mathrm{m}^{2}\right)$ & $25.51 \pm 3.58$ & $23.77 \pm 2.47$ \\
Females $(\mathrm{n} \%)$ & $196(65.33)$ & $177(59.00)$ \\
KL grade $2 / 3 / 4$ & $71 / 174 / 55$ & --- \\
VAS (mean $\pm \mathrm{SD})$ & $6.04 \pm 1.07$ & --- \\
Total womac $(\mathrm{mean} \pm \mathrm{SD})$ & $35.51 \pm 9.16$ & --- \\
\hline
\end{tabular}


Table 2. Genotype association between SNP in GDF-5 gene and Knee Osteoarthritis (KOA)

\begin{tabular}{|c|c|c|c|c|c|c|c|c|c|}
\hline & \multicolumn{3}{|c|}{ All Subjects } & \multicolumn{3}{|l|}{ Women } & \multicolumn{3}{|l|}{ Men } \\
\hline & $\begin{array}{l}\text { Control } \\
(30)\end{array}$ & Case (300) & $\begin{array}{l}\mathrm{O} R,(95 \% \\
\mathrm{CI}), \mathrm{p} \text { value }\end{array}$ & $\begin{array}{l}\text { Control } \\
(177)\end{array}$ & Case (196) & $\begin{array}{l}\mathrm{O} R,(95 \% \\
\mathrm{CI}), \mathrm{p} \text { value }\end{array}$ & $\begin{array}{l}\text { Control } \\
(123)\end{array}$ & Case (104) & $\begin{array}{l}\text { O R, }(95 \% \mathrm{CI}) \\
\text { p value }\end{array}$ \\
\hline \multicolumn{10}{|l|}{ Rs 143383} \\
\hline $\mathrm{CC}$ & $56(18.66)$ & $46(15.33)$ & 1.00, (Reference) & $36(20.33)$ & $36(18.36)$ & 1.00, (Reference) & $20(16.26)$ & $10(9.61)$ & \multirow{5}{*}{$\begin{array}{l}1.00, \text { (Reference) } \\
1.48,(0.63 \\
-3.45), 0.359 \\
2.43,(1.01 \\
-5.83), 0.046^{*} \\
1.00,(\text { Reference) } \\
1.53,(1.04 \\
-2.24), 0.030^{*}\end{array}$} \\
\hline CT & $160(5$ & $130(43.33)$ & $\begin{array}{l}1.00,(0.62 \\
-1.55), 1.000\end{array}$ & $94(53.10)$ & 81(41.32) & $\begin{array}{l}0.86,(0.49-1.49) \\
0.595\end{array}$ & $66(53.65)$ & 49(47.11) & \\
\hline TT & $84(28)$ & $124(41.33)$ & $\begin{array}{l}1.79,(1.14 \\
-2.89), 0.016^{*}\end{array}$ & $47(26.55)$ & $79(40.30)$ & $\begin{array}{l}1.63,(0.93-3.02), \\
0.083\end{array}$ & $37(30.81)$ & $45(43.26)$ & \\
\hline $\mathrm{C}$ & 272 & 22 & $1.00,($ Reference $)$ & 16 & 15 & 1.00, (Reference) & & & \\
\hline $\mathrm{T}$ & $328(54.66)$ & $378(63)$ & $\begin{array}{l}1.41,(1.12 \\
-1.78), 0.003 *\end{array}$ & $188(53.10)$ & $239(60.96)$ & $\begin{array}{l}1.38,(1.03-1.84), \\
0.030^{*}\end{array}$ & $140(56.91)$ & $139(66.82)$ & \\
\hline
\end{tabular}

* Significant $\mathrm{P}$ value

Table 3. Association of genotype with clinical score

\begin{tabular}{|c|c|c|c|}
\hline \multirow[b]{2}{*}{ Clinical score } & \multicolumn{3}{|c|}{ GDF5 (genotype distribution) } \\
\hline & $\mathrm{CC}(\%)$ & CT $(\%)$ & TT $(\%)$ \\
\hline $\mathrm{VAS} \leq 6$ & $34(15.45) \chi^{2}=9.30$ & 97(44.09) $\mathrm{P}=0.010^{*}$ & $89(40.45)$ \\
\hline VAS $>6$ & $12(15) \chi^{2}=7.29$ & $33(41.25) \mathrm{P}=0.026^{*}$ & $35(43.75)$ \\
\hline Womac $\leq 33$ & $23(14.64) \chi^{2}=11.0$ & $66(42.03) \mathrm{P}=0.004 *$ & $68(43.31)$ \\
\hline Womac $>33$ & $23(16.08) \chi^{2}=5.59$ & $64(44.75) \mathrm{P}=0.061$ & $56(39.16)$ \\
\hline
\end{tabular}

* Significant $\mathrm{P}$ value

Table 4. Association of genotype with individual radiological score

\begin{tabular}{|c|c|c|c|c|c|c|}
\hline \multirow[b]{3}{*}{ Radiological score } & \multicolumn{6}{|c|}{ Genotype Distribution (GDF-5) } \\
\hline & \multicolumn{3}{|l|}{ Left } & \multicolumn{3}{|c|}{ Right } \\
\hline & $\mathrm{CC}$ & $\mathrm{CT}$ & TT & $\mathrm{CC}$ & $\mathrm{CT}$ & TT \\
\hline Joint Space Narrowing (JSN) & & & & & & \\
\hline Absent & 17 & 39.00000 & 26.000 & 20 & 37.00000 & 36.000 \\
\hline Present & 29 & $\begin{array}{l}91.00000 \\
\chi 2=5.13\end{array}$ & $\begin{array}{l}98.000 \\
P=0.077\end{array}$ & 26 & $\begin{array}{l}93.00000 \\
\chi 2=3.96\end{array}$ & $\begin{array}{l}88.000 \\
\mathrm{P}=0.138\end{array}$ \\
\hline Osteophyte & & & & & & \\
\hline Absent & 0 & 6.00000 & 2.000 & 4 & 6.00000 & 0.000 \\
\hline Present & 46 & $\begin{array}{l}124.00000 \\
\chi 2=3.69\end{array}$ & $\begin{array}{l}122.000 \\
\mathrm{P}=0.158\end{array}$ & 42 & $\begin{array}{l}124.00000 \\
\chi 2=9.04\end{array}$ & $\begin{array}{l}124.000 \\
\mathrm{P}=0.011\end{array}$ \\
\hline Articular incongruity & & & & & & \\
\hline Absent & 14 & 26.00000 & 11.000 & 15 & 23.00000 & 15.000 \\
\hline Present & 32 & $\begin{array}{l}104.00000 \\
\chi 2=12.52\end{array}$ & $\begin{array}{l}113.000 \\
\mathrm{P}=0.002\end{array}$ & 31 & $\begin{array}{l}107.00000 \\
\chi 2=9.705\end{array}$ & $\begin{array}{l}109.000 \\
\mathrm{P}=0.008^{*}\end{array}$ \\
\hline Subchondral cyst & & & & & & \\
\hline Absent & 36 & 94.00000 & 79.000 & 33 & 94.00000 & 82.000 \\
\hline Present & 10 & $\begin{array}{l}36.00000 \\
\chi 2=4.11\end{array}$ & $\begin{array}{l}45.000 \\
\mathrm{P}=0.128\end{array}$ & 13 & $\begin{array}{l}36.00000 \\
\chi 2=1.257\end{array}$ & $\begin{array}{l}42.000 \\
P=0.530\end{array}$ \\
\hline Juxta articular osteopenia & & & & & & \\
\hline Absent & 22 & 48.00000 & 51.000 & 24 & 40.00000 & 49.000 \\
\hline Present & 24 & $\begin{array}{l}82.00000 \\
\chi 2=1.73\end{array}$ & $\begin{array}{l}73.000 \\
P=0.420\end{array}$ & 22 & $\begin{array}{l}90.00000 \\
\chi 2=6.93\end{array}$ & $\begin{array}{l}75.000 \\
\mathrm{P}=0.031\end{array}$ \\
\hline Loose bodies & & & & & & \\
\hline Absent & 43 & 126.00000 & 113.000 & 43 & 123.00000 & 115.000 \\
\hline Present & 3 & $\begin{array}{l}4.00000 \\
\chi^{2}=3.80\end{array}$ & $\begin{array}{l}11.000 \\
P=0.149\end{array}$ & 3 & $\begin{array}{l}7.00000 \\
\chi 2=0.37\end{array}$ & $\begin{array}{l}9.000 \\
P=0.827\end{array}$ \\
\hline $\begin{array}{l}\text { Extra articular calcification } \\
\text { Absent }\end{array}$ & 39 & 109.00000 & 101.000 & 40 & 110.00000 & 103.000 \\
\hline Present & 7 & $\begin{array}{l}21.00000 \\
\chi 2=0.380\end{array}$ & $\begin{array}{l}23.000 \\
\mathrm{P}=0.827\end{array}$ & 6 & $\begin{array}{l}20.00000 \\
\chi^{2}=0.398\end{array}$ & $\begin{array}{l}21.000 \\
P=0.819\end{array}$ \\
\hline Subchondral sclerosis & & & & & & \\
\hline Absent & 40 & 100.00000 & 107.000 & 40 & 106.00000 & 110.000 \\
\hline Present & 6 & $\begin{array}{l}30.00000 \\
\chi 2=4.62\end{array}$ & $\begin{array}{l}17.000 \\
P=0.099\end{array}$ & 6 & $\begin{array}{l}24.00000 \\
\chi 2=2.72\end{array}$ & $\begin{array}{l}14.000 \\
P=0.256\end{array}$ \\
\hline
\end{tabular}




\section{DISCUSSION}

Consistent with the previous reports in Caucasian and Orientals (Miyamoto et al., 2007; Southam et al., 2007), the present study has demonstrated the association between polymorphisms of GDF5 and risk of knee OA in North Indian population and supports the hypothesis that polymorphisms in GDF5 may be involved in the pathogenesis of this disease (Miyamoto et al., 2007). Our data have shown that polymorphism exist in the GDf-5 (BsiE1) gene in North Indian population. The frequency of $\mathrm{T}$ allele in our population (55\%) was similar to that reported in Caucasians (59-63\%) (Rouault et al., 2010; Southam et al., 2007; Tsezou et al., 2008; Valdes and Spector, 2009) the oriental population carry relatively higher frequency $(70-74 \%)$ of variant $\mathrm{T}$ allele (Shin et al., 2012; Cao et al., 2010; Dai et al., 2008; Miyamoto et al., 2007).

Our data have shown significant increase in the frequency of $\mathrm{T}$ allele of Gdf-5 (BsiE1) gene in KOA when compared with controls. Significant association of polymorphism in GDf-5 (BsiE1) gene has been reported in Oriental and Caucasians population (Southam et al., 2007; Valdes and Spector, 2009). Likewise Oriental (Japanese and Chinese) population also showed significant association of polymorphism in GDF-5 with knee OA (Miyamoto et al., 2007). However, inconsistent results have also been reported in those populations (Tsezou et al., 2008; Cao et al., 2010). This has been partly attributed to the smaller sample size and ethinic variations among them. Stratification of subjects on bases of sex further showed significant association of variant $\mathrm{T}$ allele with $\mathrm{KOA}$ in males and females. Similar association of variant $T$ alleles with $\mathrm{KOA}$ in males and females has been demonstrated in Caucasians and Koreans (Cao et al., 2010; Tsezou et al., 2008; Southam et al., 2007).

GDF5 has been found to be expressed in regions of future joints during early development and GDF5 mutations have been associated with abnormal joint development (Francis-West et al., 1999). GDF-5 acts at two stages of skeletal development and by two distinct mechanisms. First, GDF-5 promotes the initial stages of chondrogenesis by promoting cell adhesion, which is consistent with the expression of Gdf-5 in the cartilage condensation. Second, GDF-5 can increase the size of the skeletal elements by increasing proliferation within the epiphyseal cartilage adjacent to its expression within the joint interzone (Francis-West et al., 1999;
Buxton et al., 2001). Significant association of polymorphism in GDF-5 with KOA could be related to role of variant $\mathrm{T}$ allele to influence transcription of the GDF5 gene with the susceptible allele showing reduced transcriptional activity (Miyamoto et al., 2007). The reduced activity of GDF5 may inhibit the process of early cartilage differentiation (Hatakeyama et al., 2004). Genetic variations in the GDF5 locus have been reported to be involved in the pathogenesis of rheumatoid arthritis and to influence human height, hip axis length and fracture risk in the elderly (Rouault et al., 2010; Vaes et al., 2009). Furthermore, association of variant $T$ allele with other musculoskeletal phenotypes, including variation in Achilles tendon pathology, fracture risk and congenital dysplasia of the hip, has also been reported (Posthumus et al., 2010; Sanna et al., 2008).

Further evidence for the involvement of GDF-5 polymorphism with KOA was provided by our data indicating association of variant $(\mathrm{T})$ allele with clinical symptom of KOA. OA knee was found to be associated with both good and poor index of both VAS and WOMAC. Further, studies are however needed with a larger sample size to identify the possible role of this SNP in GDF-5 with progression of the symptom of KOA with poor and good indices of VAS and WOMAC. A summary of association of variant $\mathrm{T}$ allele of GDF-5 with Individual Radiological Features (IRF) revealed that though significant association was not found with all IRF studied; there was a significant difference between patients with and without osteophyte in individuals with right knee $\mathrm{OA}$ though no association was found in patients with osteophyte in left knee. Likewise, Juxtraarticular ostopenia was also significantly associated in right knee but not in left knee. Articular incongruity was however significantly associated in both knees, left and right knee suggesting that this polymorphism in GDF-5 is associated with radiological KOA. Sanghi et al. (2011) earlier reported that articular incongruity is a better representative of pain and stiffness and juxtra-articular osteopenia and physical disability and clinical severity in OA knee (Sanghi et al., 2011).

\section{CONCLUSION}

This study suggests the association between GDF5 polymorphisms and risk of knee OA in North Indian population and therefore supports the involvement of polymorphism in this gene in the pathogenesis of knee OA. The data suggest that Identification of genetic factors should enable better understanding of the pathogenesis of this complex disease and avoid late diagnosis and delayed treatment. 


\section{ACKNOWLEDGMENT}

We would like to thank Division of NonCommunicable Disease, Indian Council of Medical Research, New Delhi for providing us the financial grant vide their letter No. 5/4-5/2/ortho/2009-NCD-I for conducting the study. The authors are grateful to Dr AJ Khan, Mr Amit Sharma CSIR-SRF, Mr Mukesh Driwedi and Mr. B S Pandey, for their cooperation and assistance for collection of samples and in laboratory work.

\section{REFERENCES}

Aigner, T. and J. Stove, 2003. Collagens-major component of the physiological cartilage matrix, major target of cartilage degeneration, major tool in cartilage repair. Adv. Drug Deliv. Rev., 55: 15691593. DOI: $10.1016 /$ j.addr.2003.08.009

Altman, R.D., 2011. Osteoarthritis in the Elderly Population. In: Geriatric Rheumatology, Part 3, Nakasato, Y. and R.L. Yung (Eds.), Springer Press, New York, pp: 187-196.

Barlas, I.O., M. Sezgin, M.E. Erdal, G. Sahin and H.C. Ankarali et al., 2009. Association of $(-1,607) 1 \mathrm{G} / 2 \mathrm{G}$ polymorphism of matrix metalloproteinase-1 gene with knee osteoarthritis in the Turkish population (knee osteoarthritis and MMPs gene polymorphisms). Rheumatol. Int., 29: 383-388. DOI: $10.1007 / \mathrm{s} 00296-008-0705-6$

Bellamy, N., 1989. Pain assessment in osteoarthritis: Experience with the WOMAC osteoarthritis index. Semin. Arthritis, Rheum., 18: 14-17. PMID: 2786253

Bergink, A.P., J.B.V. Meurs, J. Loughlin, P.P. Arp and Y. Fang et al., 2003. Estrogen receptor alpha gene haplotype is associated with radiographic osteoarthritis of the knee in elderly men and women. Arthritis Rheum., 48: 1913-1922. PMID: 12847685

Brandt, K.D., P. Dieppe and E. Radin, 2009. Etiopathogenesis of osteoarthritis. Med. Clin. North. Am., 93: 1-24. DOI: 10.1016/j.mcna.2008.08.009

Buckwalter, J.A. and H.J. Mankin, 1998. Articular cartilage: degeneration and osteoarthritis, repair, regeneration, and transplantation. Instr. Course. Lect., 47: 487-504. PMID: 9571450

Buxton, P., C. Edwards, C.W. Archer and P. FrancisWest, 2001. Growth/differentiation factor-5 (GDF5) and skeletal development. J. Bone. Joint. Surg. Am., 83: S23-30. PMID: 11263662
Cao, Z., H.S. Lee, J.H. Song, J.W. Yoon and Y.K. Park et al., 2010. Growth Differentiation Factor 5 (GDF5) core promoter polymorphism is not associated with susceptibility to osteoarthritis of the knee in the Korean population. Korean J. Pathol., 44: 404-409. DOI: 10.4132/KoreanJPathol.2010.44.4.404

Dai, J., D. Shi, P. Zhu, J. Qin and H. Ni et al., 2008. Association of a single nucleotide polymorphism in growth differentiate factor 5 with congenital dysplasia of the hip: A case-control study. Arthritis Res. Ther., 10: R126-R126. DOI: 10.1186/ar2540

Davidson, B.E.N., E.L. Vitters, P.M.V.D. Kraan and W.B.V.D. Berg, 2006. Expression of Transforming Growth Factor-beta (TGFbeta) and the TGFbeta signalling molecule SMAD-2P in spontaneous and instability-induced osteoarthritis: Role in cartilage degradation, chondrogenesis and osteophyte formation. Ann. Rheum. Dis., 65: 1414-1421. DOI: 10.1136/ard.2005.045971

Ding, C., J.M. Pelletier, J.P. Pelletier, F. Abram and J.P. Raynauld et al., 2008. Two-year prospective longitudinal study exploring the factors associated with change in femoral cartilage volume in a cohort largely without knee radiographic osteoarthritis. Osteoarthritis Cartilage, 16: 443-449. PMID: 17892953

Francis-West, P.H., A. Abdelfattah, P. Chen, C. Allen and J. Parish et al., 1999. Mechanisms of GDF-5 action during skeletal development. Development, 126: 1305-1315. PMID: 10021348

Gomez-Barrena, E., O. Sanchez-Pernaute, R. Largo, E. Calvo and P. Esbrit et al., 2004. Sequential changes of Parathyroid Hormone related protein (PTHrP) in articular cartilage during progression of inflammatory and degenerative arthritis. Ann. Rheum. Dis., 63: 917-922. PMID: 15249318

Green, G.A., 2001. Understanding NSAIDs: From aspirin to COX-2. Clin. Cornerstone, 3: 50-60. PMID: 11464731

Hardingham, T.E., M.T. Bayliss, V. Rayan and D.P. Noble, 1992. Effects of growth factors and cytokines on proteoglycan turnover in articular cartilage. Br. J. Rheumatol., 31: 1-6. PMID: 1532522

Hatakeyama, Y., R.S. Tuan and L. Shum, 2004. Distinct functions of BMP4 and GDF5 in the regulation of chondrogenesis. J. Cell Biochem., 91: 1204-1217. PMID: 15048875

Jin, S.Y., S.J. Hong, H.I. Yang, S.D. Park and M.C. Yoo et al., 2004. Estrogen receptor-alpha gene haplotype is associated with primary knee osteoarthritis in Korean population. Arthritis Res. Ther., 6: R415R421. PMID: 15380041 
Kizawa, H., I. Kou, A. Iida, A. Sudo and Y. Miyamoto et al., 2005. An aspartic acid repeat polymorphism in asporin inhibits chondrogenesis and increases susceptibility to osteoarthritis. Nat. Genet., 37: 138144. PMID: 15640800

Mabuchi, A., N. Manabe, N. Haga, H. Kitoh and T. Ikeda et al., 2003. Novel types of COMP mutations and genotype-phenotype association in pseudoachondroplasia and multiple epiphyseal dysplasia. Hum. Genet., 112: 84-90. PMID: 12483304

Miyamoto, Y., A. Mabuchi, D. Shi, T. Kubo and Y. Takatori et al., 2007. A functional polymorphism in the 5' UTR of GDF5 is associated with susceptibility to osteoarthritis. Nat. Genet., 39: 529-533. PMID: 17384641

Posthumus, M., M. Collins, J. Cook, C.J. Handley and W.J. Ribbans et al., 2010. Components of the transforming growth factor-beta family and the pathogenesis of human Achilles tendon pathology--a genetic association study. Rheumatol. (Oxford), 49: 2090-2097. DOI: 10.1093/rheumatology/keq072

Rouault, K., V. Scotet, S. Autret, F. Gaucher and F. Dubrana et al., 2010. Evidence of association between GDF5 polymorphisms and congenital dislocation of the hip in a Caucasian population. Osteoarthritis Cartilage, 18: 1144-1149. DOI: 10.1016/j.joca.2010.05.018

Sanghi, D., S. Avasthi, A. Mishra, A. Singh and S. Agarwal et al., 2011. Is radiology a determinant of pain, stiffness, and functional disability in knee osteoarthritis? A cross-sectional study. J. Orthop. Sci., 16: 719-725. DOI: 10.1007/s00776-011-0147-y

Sanna, S., A.U. Jackson, R. Nagaraja, C.J. Willer and W.M. Chen et al., 2008. Common variants in the GDF5-UQCC region are associated with variation in human height. Nat. Genet., 40: 198-203. DOI: 10.1038/ng.74

Sharma, M.K., H.M. Swami, V. Bhatia, A. Verma, S. Bhatia and G. Kaur, 2007. An epidemiological study of correlates of osteo-arthritis in geriatric population of UT Chandigarh. India J. Comm. Med., 32: 77-8. DOI: 10.4103/0970-0218.53414

Shin, M.H., S.J. Lee, S.J. Kee, S.K. Song and S.S. Kweon et al., 2012. Genetic association analysis of GDF5 and ADAM12 for knee osteoarthritis. Joint. Bone. Spine. DOI: 10.1016/j.jbspin.2011.10.016
Southam, L., J.R. Lopez, J.M. Wilkins, M. PomboSuarez and S. Snelling et al., 2007. An SNP in the 5'-UTR of GDF5 is associated with osteoarthritis susceptibility in Europeans and with in vivo differences in allelic expression in articular cartilage. Hum. Mol. Genet., 16: 2226-2232. PMID: 17616513

Tchetina, E.V., 2011. Developmental mechanisms in articular cartilage degradation in osteoarthritis. Arthritis, 2011: 683970-16. DOI: $10.1155 / 2011 / 683970$

Tchetina, E.V., J. Antoniou, M. Tanzer, D.J. Zukor and A.R. Poole, 2006. Transforming growth factor-beta2 suppresses collagen cleavage in cultured human osteoarthritic cartilage, reduces expression of genes associated with chondrocyte hypertrophy and degradation, and increases prostaglandin $\mathrm{E}(2)$ production. Am. J. Pathol., 168: 131-140. PMID: 16400016

Tetlow, L.C., D.J. Adlam and D.E. Woolley, 2001. Matrix metalloproteinase and proinflammatory cytokine production by chondrocytes of human osteoarthritic cartilage: Associations with degenerative changes. Arthritis Rheum., 44: 585594. PMID: 11263773

Tsezou, A., M. Satra, P. Oikonomou, K. Bargiotas and K.N. Malizos, 2008. The growth differentiation factor 5 (GDF5) core promoter polymorphism is not associated with knee osteoarthritis in the Greek population. J. Orthop. Res., 26: 136-140. PMID: 17676627

Vaes, R.B., F. Rivadeneira, J.M. Kerkhof, A. Hofman and H.A. Pols et al., 2009. Genetic variation in the GDF5 region is associated with osteoarthritis, height, hip axis length and fracture risk: The Rotterdam study. Ann. Rheum. Dis., 68: 1754-1760. DOI: 10.1136/ard.2008.099655

Valdes, A.M. and T.D. Spector, 2009. The contribution of genes to osteoarthritis. Med. Clin. North. Am., 93: 45-66. DOI: 10.1016/j.mcna.2008.08.007

Valdes, A.M. and T.D. Spector, 2011. Genetic epidemiology of hip and knee osteoarthritis. Nat. Rev. Rheumatol., 7: 23-32. DOI: 10.1038/nrrheum.2010.191

Watanabe, H., Y. Yamada and K. Kimata, 1998. Roles of aggrecan, a large chondroitin sulfate proteoglycan, in cartilage structure and function. J. Biochem., 124: 687-693. PMID: 9756610 